\title{
The Fabrication of $\mathrm{NiO}$ Microtubes Using Bacillus subtilis Bacteria
}

\author{
F.E. Atalay ${ }^{a}$, D. $\operatorname{Asma}^{b}$, E. Aydogmus ${ }^{a}$, H. Turanci ${ }^{b}$ And H. KayA ${ }^{a}$ \\ ${ }^{a}$ Inonu University, Science and Art Faculty, Department of Physics, Malatya 44280, Turkey \\ ${ }^{b}$ Inonu University, Science and Art Faculty, Department of Biology, Malatya 44280, Turkey
}

\begin{abstract}
The nickel oxide microtubes with high surface-to-volume ratio have been achieved using the Bacillus subtilis bacteria. Surface properties of the metal-oxide nanostructured materials were investigated by electron microscopy. The surface area of that was also studied by the Brunauer-Emmett-Teller analysis method. The materials were used at the construction of supercapacitor as an electrode active material.
\end{abstract}

DOI: $10.12693 /$ APhysPolA.125.235

PACS: 81.07.-b, 82.47.Uv, 88.80.fh

\section{Introduction}

Today, the most of the energy are obtained from coal, oil, natural gas, and nuclear energy. Recently, the fear of extinction of these sources has led to the search for new energy sources. The search for new sources of energy, inherent in the world of solar energy, wind energy, and geothermal energy are among those considered in the first place. However, such energies are not common and cheap. To store electrical energy using capacitors has been studied intensively in the last thirty years [1-6]. Depending on the development of technology, the desired electrode materials contain generally nanoparticles with high surface area and high energy density. In addition, other important features for supercapacitors is long life, low cost, and stability.

In this project, we produced $\mathrm{NiO}$ nanostructured electrode materials by using the most common life forms known in nature as bacteria. The highest specific capacitance, $343 \mathrm{~F} / \mathrm{g}$, was observed at constant currentdischarge with a current $0.35 \mathrm{~mA} / \mathrm{g}$ in $6 \mathrm{M} \mathrm{KOH}$.

\section{Experimental}

Gram positive bacterium, Bacillus subtilis (ATCC 6633) cells were incubated at $37^{\circ} \mathrm{C}$ and $200 \mathrm{rpm}$ for overnight in a shaking incubator at liquid medium of the nutrient broth. When the optical density of the culture reached $0.3-0.6$ value, it was transferred into $250 \mathrm{ml}$ flasks containing $50 \mathrm{ml}$ nutrient broth. Cultures were agitated on rotary shaker at $200 \mathrm{rpm}$ for $5 \mathrm{~h}$, then subculturing was obtained. The bacterial cultures were centrifuged at $9000 \mathrm{rpm}$ for $10 \mathrm{~min}$ at $4{ }^{\circ} \mathrm{C}$. The cultures were resuspended in distilled water to adjust the optical density (OD $600 \mathrm{~nm}$ ) to approximately 2.0. Later $200 \mathrm{ml}$ of $250 \mathrm{mM} \mathrm{NiCl} 2$ solution was added to cultures at $10 \mathrm{ml} / \mathrm{min}$ by using burette. The mixture was continuously stirred at $800 \mathrm{rpm}$ at room temperature. After the mixture was stirred $30 \mathrm{~min}, 100 \mathrm{ml}$ of $25 \mathrm{mM} \mathrm{NH}_{4} \mathrm{OH}$ solution was also added to mixture at $10 \mathrm{ml} / \mathrm{min}$. All solutions were prepared by dissolving reagent-grade chemicals in deionised water. The $\mathrm{NH}_{4} \mathrm{OH}$ was used as reducing agent. The result mixture was continuously stirred at
$800 \mathrm{rpm}$ for $36 \mathrm{~h}$. This was followed by centrifugating and collecting of precipitate. $\mathrm{Ni}(\mathrm{OH})_{2}$ /bacteria precipitate was washed thoroughly with deionized water twice and then ethanol. Later, the formed $\mathrm{Ni}(\mathrm{OH})_{2}$ tubes precipitate dried for $24 \mathrm{~h}$ in an oven at $60^{\circ} \mathrm{C}$. It was heated from room temperature to $360^{\circ} \mathrm{C}$ in air at a rate of $1^{\circ} \mathrm{C} / \mathrm{min}$ and maintained for $12 \mathrm{~h}$. This was followed by cooling to room temperature at a rate of $10^{\circ} \mathrm{C} / \mathrm{min}$. Later the $\mathrm{Ni}$ foam was degreased with acetone, etched with $3 \mathrm{M} \mathrm{HCl}$ for $10 \mathrm{~min}$, and washed thoroughly with deionized water and acetone, again deionized water. Subsequently, the nanostructured $\mathrm{NiO}$ microtubes (75\%), acetylene black $(20 \%)$ and PTFE (5\%) were grinded and mixed in a $\mathrm{Zr}_{2} \mathrm{O}_{3}$ mortar for $30 \mathrm{~min} .4 .7 \mathrm{mg}$ of this mixed material was placed on Ni foam sheet and compressed at a pressure of $10 \mathrm{MPa}$ for $10 \mathrm{~min}$. Ni foam was used as the current collector. The finally obtained material was used as a cathode, with an exposed area of approximately $1 \mathrm{~cm}^{2}$ for the capacitance measurement. A three-electrode cell was used for the electrochemical experiments. The volume of the electrochemical bath was approximately $60 \mathrm{ml}$. An $\mathrm{Ag} / \mathrm{AgCl}$ ceramic electrode (with ceramic frit, ALS, saturated $\mathrm{KCl}$, and $-45 \mathrm{mV}$ versus $\mathrm{SCE}$ at $25^{\circ} \mathrm{C}$ ) was used as the reference electrode. A platinum electrode approximately $1 \mathrm{~cm}^{2}$ was used as an auxiliary electrode. The used electrolyte was $6 \mathrm{M} \mathrm{KOH}$.

Optical density of bacterial cultures was measured by UV-visible spectrophotometer (SHIMADZU, UV-1601). Capacitive properties of this bio-based supercapacitor was investigated by electrochemical impedance spectroscopy (EIS), galvanostatic charge-discharge tests and cyclic voltammetry (CV) method by using an electrochemical analyzer system, namely an Iviumstat potentiostat/galvanostat. The frequency limits were typically set between $10 \mathrm{mHz}$ and $100 \mathrm{kHz}$. The AC oscillation amplitude was $5 \mathrm{mV}$. Surface properties of the $\mathrm{NiO}$ microtubes were investigated by scanning electron microscopy (SEM; JEOL JSEM 7001F). The surface area of that was also studied by the Brunauer-Emmett-Teller (BET) analysis method by Micromeritics TriStar 3000 (V3.01) system (DFT Plus ${ }^{\circledR}$ V2.02). 


\section{Results and discussion}

Figure 1 shows the SEM images of obtained NiO structures. SEM image of single microtube is shown in Fig. 1b. It can be seen in the figures that the microtubes have a diameter of $1 \mu \mathrm{m}$ and length $5-6 \mu \mathrm{m}$. Also the external surface of microtubes have porous and nanoflake structure (inset of Fig. 1b).

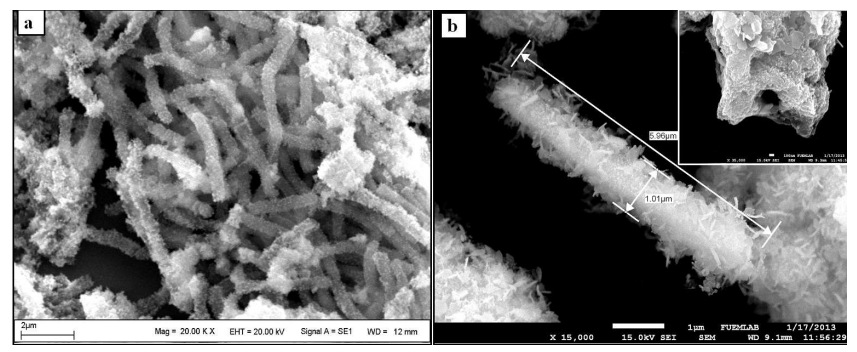

Fig. 1. SEM images of nanostructured NiO microtubes.

The specific surface area of the annealed nanostructured $\mathrm{NiO}$ microtubes was characterized using nitrogen gas sorption. Figure 2 shows the nitrogen adsorption isotherms of the annealed sample. The measured BET surface area of sample is $c a .49 \mathrm{~m}^{2} / \mathrm{g}$. The inset in Fig. 2 shows the pore size distribution plots calculated using the Barrett--Joyner-Halenda equation from the adsorption branch of the isotherms. The nitrogen adsorption isotherms and pore size distribution measurement indicate that the sample have porous structure mainly composed of mesopores with the average pore diameter around $25 \mathrm{~nm}$.

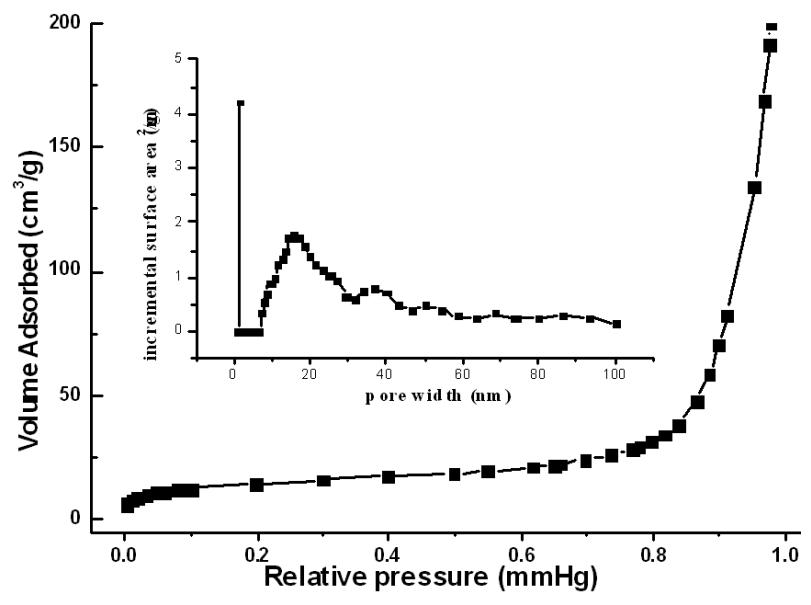

Fig. 2. Nitrogen adsorption isotherm of nanostructured $\mathrm{NiO}$ microtubes. Inset shows the pore size distribution of $\mathrm{NiO}$ nanostructures.

Figure 3 shows the CV curves measured for nanostructured $\mathrm{NiO}$ electrode at different scan rates. CV curves for PTFE and acetylene black electrode surface and Ni foam electrode surface at $10 \mathrm{mV} / \mathrm{s}$ show that the redox signal did not occur. The $\mathrm{CV}$ curves also indicate that the electrochemical capacitance of the $\mathrm{NiO}$ samples mainly results from the pseudocapacitance, which is based on redox mechanism. The area under curves increases with the potential scan rate. It is found that the increases in the CV currents are linearly proportional to the increase in the scan rate, reflecting fast electrochemical reaction process of the nanostructured $\mathrm{NiO}$ electrode. The inset in Fig. 3 shows the effect of scan rate on the cathodic peak currents obtained from CV. The charge-storage mechanism of $\mathrm{NiO}$ is not through a surface redox reaction at the interface but a diffusion controlled reaction $[5,6]$.

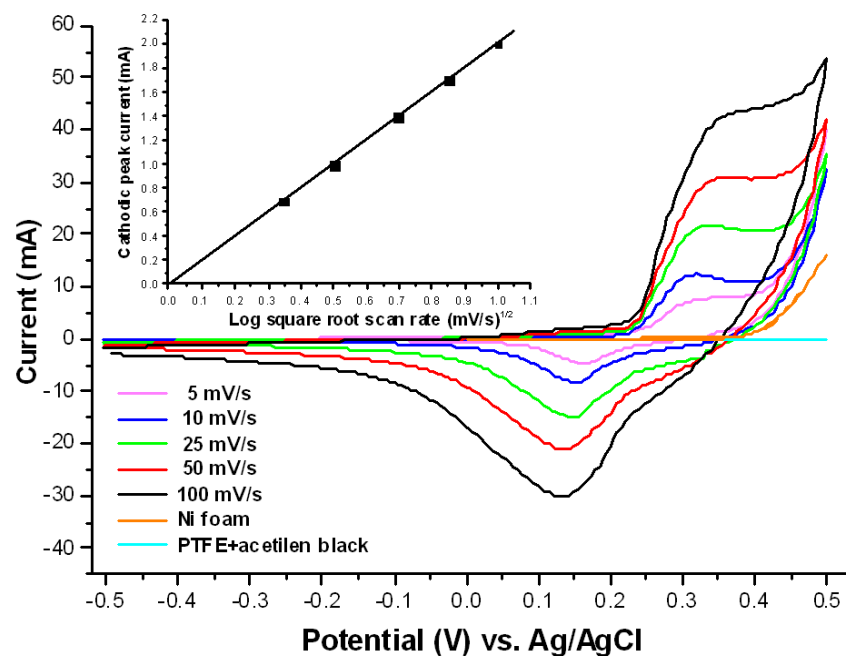

Fig. 3. $\mathrm{CV}$ curves of $\mathrm{NiO}$ electrodes at different scan rates. The inset shows cathodic peak current as a function of the square root of the scan rate.

The long term galvanostatic cycling stability of $\mathrm{NiO}$ electrode was investigated over 750 cycles as shown in Fig. 4. The inset of Fig. 4 shows ten charge and discharge curves of $\mathrm{NiO}$ electrode at $0.35 \mathrm{~mA}$ over the operating potential range $0-0.38 \mathrm{~V}$ (vs. $\mathrm{Ag} / \mathrm{AgCl}$ ). The discharge specific capacitance in the first cycle was $343 \mathrm{~F} / \mathrm{g}$. The capacitance of $\mathrm{NiO}$ electrode decreased gradually during the first 400 cycles and then reached the approximately stable value of $343 \mathrm{~F} / \mathrm{g}$. Voltammetric and galvanostatic results indicate that the porous structure of the $\mathrm{NiO}$ microtubes play is mainly responsible for obtaining optimum capacitance values. It exhibits good performance with a high specific capacitance of $246 \mathrm{~F} / \mathrm{g}$ after 750 charge/discharge cycles, corresponding to retention of $74 \%$ of the maximum capacitance.

Figure 5 presents the impedance spectra of $\mathrm{NiO}$ electrode at open circuit potential. These impedance plots were measured after 5 or 750 continuous charge and discharge cycles. As shown in Fig. 5, typical linear behavior at the low frequency range of electrochemical capacitors was observed in the Nyquist plot, where the slope gradually changes from $55^{\circ}$ to $67^{\circ}$ with the increase of cycles. The phase angle for the impedance plot of the $\mathrm{NiO}$ electrode was observed to be higher than $45^{\circ}$ in the low frequencies, suggesting that the electrochemical capaci- 


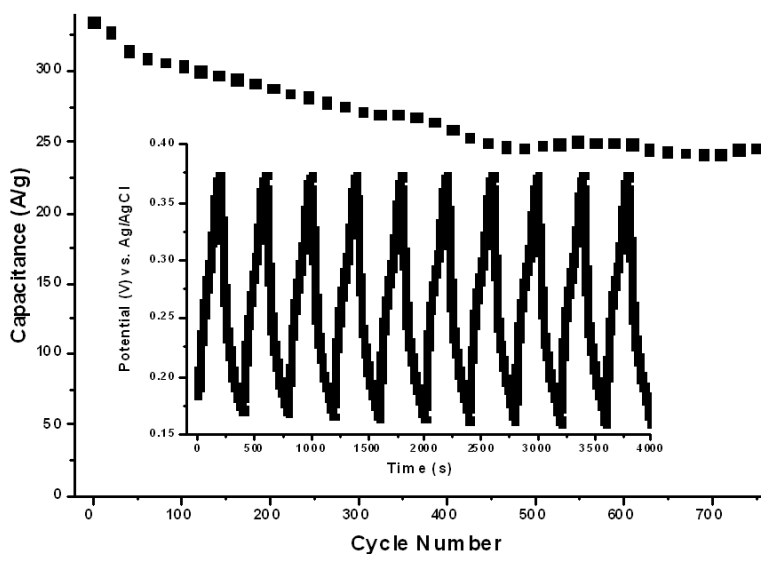

Fig. 4. The variation of specific capacitance as a function of cycle number of $\mathrm{NiO}$ electrode. The inset shows the ten cyclic charge-discharge curves.

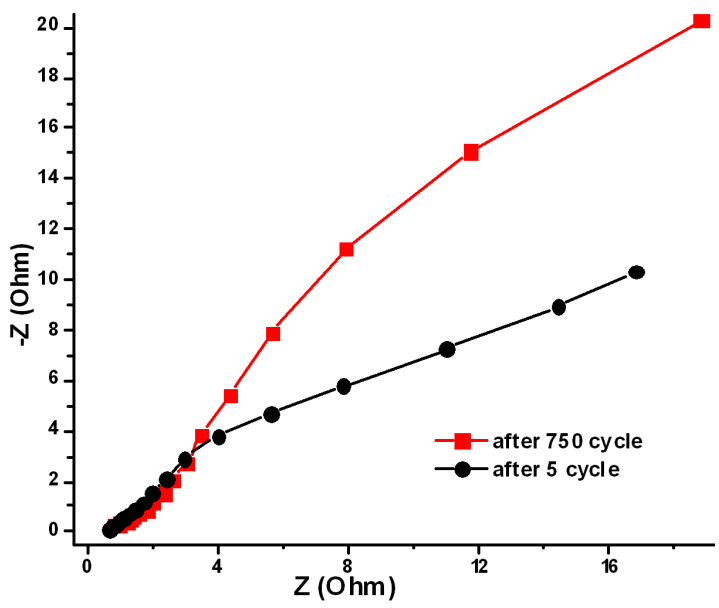

Fig. 5. Nyquist plots of $\mathrm{NiO}$ electrode at open circuit potential in $6 \mathrm{M} \mathrm{KOH}$ solution. tive behavior of the $\mathrm{NiO}$ nanostructured electrode is not controlled by diffusion process [6].

\section{Conclusion}

In summary, bio-template based approach for generating $\mathrm{NiO}$ microtubes with nanoporosity has been described. Electrochemical data demonstrated that the porous nanostructured $\mathrm{NiO}$ electrodes could deliver a maximum specific capacitance of $343 \mathrm{~F} / \mathrm{g}$ at current density $0.35 \mathrm{~F} / \mathrm{g}$. The Coulombic efficiency remains above $74 \%$ within 750 cycles. These good electrochemical capacitive properties coupled with the low cost of the bio-template based approach may offer the new possibilities for supercapacitor electrode design.

\section{Acknowledgments}

This work was supported by Inonu University with project number I.U.A.F- $2013 / 78$.

\section{References}

[1] B.E. Conway, Electrochemical Supercapacitors: Scientific Fundamentals and Technological Applications, Kluwer Academic/Plenum Pub., New York 1999.

[2] X. Zhao, B.M. Sanchez, P.J. Dobson, P.S. Grant, Nanoscale 3, 839 (2011).

[3] M. Jayalakshmi, K. Balasubramanian, Int. J. Electrochem. Sci. 3, 1196 (2008).

[4] H.-W. Shim, Y.-H. Jin, S.-D. Seo, S.H. Lee, D.-W. Kim, ACS Nano 5, 443 (2011).

[5] V. Yagmur, F.E. Atalay, H. Kaya, D. Avcu, E. Aydogmus, Acta Phys. Pol. A 123, 215 (2013).

[6] J. Xu, L. Gao, J. Cao, W. Wang, Z. Chen, Electrochim. Acta 56, 732 (2010). 